IEEE Trans, on Nucl. Sci.

Presented at 1974 Nucl sar Sclence

Symposium \& 14th Seintillation \&

Semiconductor Counter Symposium,

Washington, D. C., Dec. 11-13, 1974.

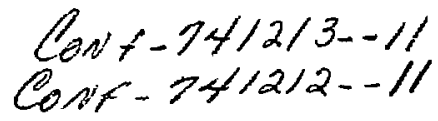

A TWO-DINENSIONAL POSITION-SENSITIVE DETECTOR

FOR THERMLI REUTRONS*

J. Alberi, J. Fischer, V. Radeka,

L. C. Rogers and B. Schoenborn

Brookhaven National Laboratory

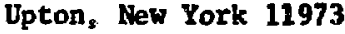

December 1974

* This work was performed under the auspices of the

v. S. Atomic Energy Commisbion. 


\title{
A TWO-DIMENSIONAL POSITION-SENSITIVE DETECTOR FOR THERMAL NEUTRONS*
}

\author{
J. Alber 1, J. Fischer, Y. Redeks, \\ L. C. Rogers and B. Schoenborn
}

Brookhaven National Laboratory

Upton, New York 11973

\begin{abstract}
We have developed and tested a thermal neutron, twodimensional position-sensitive detector for use in neutron scattering from biological samples. The tetector is based on a multi-wire proportional concept with a gas f1lling of 6 atmos. He 3 atmos. $A$, and 0.5 atros. $\mathrm{CO}_{2}$. The position readout uses a resistive wire with charge division to determine position. We have measured a resolution of less than 3 mr (FWHN) with a detection effictency of $70 \%$ at 2.8 neutrons. Considerations leading to an optimal configuration are discussed.
\end{abstract}

\section{Introduction}

Position-sensitive detector systems for neucron scattering are a continuing need in neutron diffraction experiments. 1 Many possibilities suggest themselves as the method best suited to fulfill this need. of these methods, we belleve rhat gas discharge detection of neutron-induced charged particle reactions is the method of cholce under exiating technology for the detection of thermal neutrons. Of the fossible types of gas discharge chambers, practical considerations, such as game ray background discrimination and count rate capacity, 21mit consideration of a practical detector to two types of chamber (a) Ionization (non-multiplicative) and (b) proportional (multiplicative). Of the two types of chamber, we have chosen the proportional due to larger algnalproduch capacity coupled with sufficlent energy resolution. The former attribute reduces the burden on the position sensing system while the latter enables the rejection of background gamma rays. Table I lists three charged particle reactions that are suitable for use in a gas discharge chamber to detect thermal neutrons, of the three, only $\mathrm{He}^{3}$ and $\mathrm{B}^{10}$ in the form of $\mathrm{BF}_{3}$ are of practical use. The $\mathrm{He}^{3}(n, p) T$ reaction has a reaction energy of $764 \mathrm{keV}$ and a cross section of 5327 barns. The $B^{10}(n, a) L^{7}$ reaction has a reaction energy of $2.79 \mathrm{MeV}$ and a crose section of 3840 barns. ${ }^{5}$ We have chosen the former due to its ability to operate at high pressures and relatively low voltages with good multiplication and to its high thermal neutron cross section.6,7,8,9 The relatively low reaction energy is not a liability ence there is aufficient gas gain available in the chamber. There are several methodo in use today of reading the pusition of the neutron induced reaction from the chamber. 10-18,27 Primary among these methods are (a) one amplifler-discriminator per wire; (b) delay line posicion ensing (whether de coupled or capacitively coupled); (c) resistive wire (whether charge division or diffusive RC delay lines). The method of charge division of signals from a resistive whe readout is

This report was prepared as an account of work sponsored by the United States Governnient. Noither the United States nor the United States Energy Research and Development Administration, nor any of their employees, nor any of their contractors, subcontractors, or thetr employees, confractors, warranty, express or implied, or assumes any tony liability or responsibility for the ar assumes ony legal or usefulass of any in ror the accuracy, completeness or usefulness of any information, apparatus, producl or process disclosed, or represents that its use would not infringe privately owned rights. particularly sulted to high pressure proportional chambers where signal rlae times are blow. Non-dispersive delay lines do not offer oufficient delay per unit length to give adequate spatial resolution with the poor time resolution Inherent in such slow rise signals. Even if such delay lines were avallable, the count rate capability of such a system would suffer due to the long event-processing time. The count rate capacity of the charge division readout is conparable to the charge collection time in a high pressure detector, and is sufficlent to the needs of neutron diffraction studies at an economical cost. Charge division is understood theoretically, and the realization of a sufficiently fast divider is feasible as we shall demonstrate below. Hence, we have adopted this method as the basis for position readout in our detector.

Herein, we report the development of a neutronsensitive, pogition-sensitive detector based on a tenatmosphere, $\mathrm{He}^{3}$ and $\mathrm{A}$-filled, multisire proportiona $\mathrm{I}$ chamber with resistive wire regdout. Such a counter yields basic parame ters of $70 \%$ neutron efficiency at 2.8 neutrun-wavelength and $3 \mathrm{~mm}$ useful spatial resolution at FWHM along the coordinate parallel to the anode wires. The orthogonal coordinate is spatially quantized by the anode wires.

\section{Detecter}

Figure 1 shows a schematic diagram of the multiwire proportional chamber geometry. The basic configuration consists of three wire planes with the anode at the center and two cathodes, one above and one below the anode. Each electrode is supported by a separate glass frame whose incerior dimensions are $1 \mathrm{~B} .5 \mathrm{~cm}(3.3 \mathrm{in.)}$ 8quare. Thus the sentitive region of the chamber measures approximately $18 \mathrm{~cm} \times 18 \mathrm{~cm}$. Glass is used as the support of each electrode to reduce the possibility of contamination of the gases by outgassing of electronegative materfals. In a closed system, over a long period of time, such cutgassing could poison the chamber to the extent of rendering electron collection and gas multiplication impossible. Glass frames also have the advantage of reducing the hydrogenated materials in the chamber to a minimum; hence the sensitivity to any fast neutron flux component is minimized. The wixes were wound on the frames by conventional winding techniques. The anode consists of 20 pin $(0.000 B$ In.) jiameter stainless steel wire with a spacing between wires of $2.54 \mathrm{~mm}$ (0.1 in.). Each cathode was fabricated of $100 \mu \mathrm{m}(0.004 \mathrm{in.)}$ diameter wire attached in the $218-2 a g$ fashion shown in

\footnotetext{
* This work was performed under the auspices of the
} v. S. Atomic Energy Commission.$$
+
$$

There exist several classical texts on gas discharge radiation detectors. We $118 t$ some ss Refs, (2), (3), (4). 
Fjg. 1 (a). 19 Thus each cathode forms one long resibtive readout wire with a total resistance of approximately 3000 ohms. The spacing between each readout wire is 1.27 $\mathrm{mm} .(0.05 \mathrm{in}$.$) . The use of a single, long resistive wire$ for readout aimplifies the construction procedures used in this chamber, and, as we shall show later, the relacively low resiatance does not adversely affect the position resolution of the chamber. Interelectrode spacing is $3.18 \mathrm{~mm} .(0.125 \mathrm{1n}$.$) , and there 1 \mathrm{~s}$ an additional 3.18 $\mathrm{Inm}$, between the cathode planes and the grounded surface of the pressurn vesse1. Charge from $\mathrm{He}^{3}$ reaction product ionization $1 \mathrm{~s}$ drifted intu the interplane region from the drift space (Fig. Ib) by sn electric fleld equivalent to that between the cathode-anode planes.

The three planes are asgembled, as shown in Fig. 1a, and placed $\mathrm{in}$ an aluminum container capable of withstanding overpressures of $150 \mathrm{psig}$. Small gaps between the frames supporting the three electrodes were filled with a silicone rubber compound to prevent the high electric flelds associated with edge breakdown. The entrance window of the pressure container is $0.95 \mathrm{~cm}(0.375 \mathrm{in}$.) thick and matched to the active area of the chamber. With this window, $8 \%$ of the incident neutrons are scattered out of che beam, assuming a scattering cross section of 1.46 barns for aluminum at thermal energy. Since the scattering ia lootrop 1c, approximately one half of the scattered neutrons will be detected in the counter, increasing the background. In general, the effect of this scatter is to produce broader non-gaussian talls to the position resolution function.

The gas uaed in fllling the chamber must be of exceptionally high purity to yield good results at pressures of 10 atmospheres. High impurity levels, especially of water and oxygen, can cause electron trapping with consequent degradation in charge collection. The argon and carbon dioxide are batch analyzed by the manufacturer and found to have the following impuritles: argon, $\mathrm{O}_{2}<0.5 \mathrm{ppm}, \mathrm{N}_{2}<1 \mathrm{ppm}$, sew point $-105^{\circ} \mathrm{F}$, and tota1 hydrocarbons $<0.5 \mathrm{ppm} ;$ carbon dioxide, $0_{2}<0.5 \mathrm{ppm}$, $\mathrm{N}_{2}<5.6 \mathrm{ppm}$, dew point $-130^{\circ} \mathrm{F}$ and total hydrocarbons $<0.5 \mathrm{ppm}$. The $\mathrm{He}^{3}$, as supplied by the manufacturer, contains $10^{3} \mathrm{ppm}$ of unknown impurtties. To remove the electronegative fraction of these, the helium is heated to $600^{\circ} \mathrm{C}$ in a calcium loaded purifier and held for 30 minutes. 20 After cooling, the gas is inserzed inco the detector without any further purification. The chamber was filled with 6 atmos. He ${ }^{3}, 4$ atmos. $A$, and 0.5 atmos. $\mathrm{CO}_{2}$. Energy spectra obtained with the detector with this gas mixture are consistent with those shown in Refs. (6-9) and, hence we conclude the gas is sufficiently F're for our application.

Outgassing of electronegative materials and leaks of noble gases at high pressures are always difficult problems when attempting to develop a high pressure, nonflowing gas proportional detector. We have measured the leak rate of our detector with a helium leak detector to be $5 \times 10^{-6} \mathrm{std}$. cc/sec. Thus we should lose approsimately $0.25 \%$ of the filling gas/month. Chamber outgassing 1 imits the useful life of the gas to approximately 4 months between refillings. We are presently developing a "getter" type purifier on the detector to extend this time.

\section{Neutron Detection Effictency, Product Particle $R$ inge and Position Resolucion Function}

Unlike $\mathrm{He}^{3}$ detectors without poaition sensitivity, where the range of the charged particles is unimportant (except to the extent that wall alid end effects become important), position sensitive detectors require that the particles be stopped within the desired spatial resolution of the chamber. 21 Unfortunately $\mathrm{He}^{3}$ by itself is not sufficiently dense at reasoriable working pressure to stop the proton from the $\mathrm{He}^{3}(n, p) \mathrm{H}^{3}$ reaction in a reasonable distance. At 10 atmospheres the range of a $573 \mathrm{keV}_{2}$ proton in $\mathrm{He}^{3}$ is $1.045 \mathrm{mg} / \mathrm{cm}^{2}$ or approximately $7.9 \mathrm{~mm} .{ }^{22}$ The $\mathrm{H}^{3}$ ion range is approximately one-half that of the priton. Hence the proton range dominates. Thus there is an obvious need for a gas whose function is to stop the charged particles resulting from the detection reaction. We have conflicting requirements on gas composition which must be resolved, i.e., high percentage of $\mathrm{He}^{3}$ for detection efflciency vs. a high percentage of some denser gas for increased charged particle stopping-power. Increasing the working pressure of the chamber is a partial solution to this problem. However, mechanical limitations of the pressure vessel as well as charge collection and multiplication at high pressures in large chambers limit the pressure to approximately 10 atmospheres. A reasonable compromile of these factors is thus necessary to obtain performance characteristics that are satisfactory for small angle neutron diffraction scattering experiments.

Argon, a gas whose electron transport and multiplication properties are well known, has been chosen for the stopping gas in the detector. $2,3,4$ In choosing a dense gas to stop tine $\mathrm{He}^{3}$ reaction products, the gammaray sensitivity of the detector, which arises from different detector elements at different incitent energy, must also be considered. However, upon noting that the dependence on the atomic number, $Z$, of the photoelectric cross section is $Z^{4.5}$, of the Compton crcss section is $Z$, and of the proton range is $2^{-\frac{1}{2}}$, we have concluded that argon is preferable to denser noble gasses.22,23 At gamma-ray energies below $200 \mathrm{keV}$, where most interactions are in the detector gas, argon has low photoelectric and Compton cross sections, At higher energy ( $1 \mathrm{MeV}$ ), where most detected gamma-ray events are caused by electrons recolling from the detector walls, the fonization from the electron is higher in heavier gases, causing more neasured charge.

Figure 2 shows calculated detector efficiency vs. neutron wavelength for a gas filling of $40 \%$ argon and $60 \% \mathrm{He}^{3}$ by volume at 10 atmospheres. The efficiency for $4 \AA$ neutrons is $91 \%$, and for $1.82 \AA$ reutrons (thermal) is $67 \%$. The ee efficiencles are more than sufficient for our application in biological neutron scattering. Figure 3 shows detection efficiency of 4 i neutron vs. gas composition at 10 atmospheres pressure (curve A) and proton range vs. gas composition at 10 atmospheres pressure for two gases, argon and krypton, (curves $B$ and C). The calculated value for proton range under the operating characteristics of the chamber ( 6 atmospheres $\mathrm{He}^{3}{ }_{1}, 4$ atmoopheres $\mathrm{A}, 0.5$ atmoophere $\mathrm{CO}_{2}$ ) yields a proton range from the $\mathrm{He}^{3}(\mathrm{n}, \mathrm{p}) \mathrm{H}^{3}$ reaction of $2.3 \mathrm{~mm}$. The accuracy of this figure is difficult to assess due to the lack of primary data. 22 However, we shall compare it to our observed spatial resolution in a later section.

From the above, it becomes possible to calculate the spatial resolution functiun for the proton and triton produced from the $\mathrm{He}^{3}$ reaction. If we examine the paths of the charged particles emitted from a small volume of space $\Delta V$ in which neutrons are captured, it is clear from the kinetics that the proton and triton are emitted back to back and the direction of proton emission is isotropic. The proton, whose energy is $573 \mathrm{keV}$, has; a range $\sim 2$ times as great as the triton, whose energy is $191 \mathrm{keV}$. Thus for neutrons captured in any small volume of space $\Delta V$, the resultant ionization from many such captures will form a spherically symmetric distribution about the capture point. The radial dependence of the ionization 
distribution will be complicated by the multiparticle emission and the spatially non-uniform apecific ionizacion from these particles. We may, however, write a general expression for the spatial resolution function projected to one cinension, $D(p)$, caused by this lonization cloud. In general,

$$
D(p)=2 \pi \int_{0}^{\infty} \int_{0}^{\pi} r^{2} d r \sin \theta d \theta f(r) \delta(p-r \cos \theta)
$$

where $p=$ the spatial coordinate,

$f(r)$ = the function describing che radial dependence of specizic ionization caused by the proton and triton,

$$
r, \theta=\text { variables of integration, }
$$$$
6 \text { Dirac } 8 \text {-function. }
$$

The integral sums tonization over planes parallel to the $x$ and $y$ axis and at distance $p$ above the origin. This formula may be further simplified by performing the integration over $\theta$. Namely,

$$
D(p)=2 \pi \int_{p}^{\infty} r d r f(r)
$$

If one makes the simplifying assumption that $f(r)$ is a uniform function of $r$ with value $\phi$ up to some cutof $f$ value $R$, the resolution function becomes

$$
D(p)=\pi \phi\left(R^{2}-p^{2}\right), R \geq p \geq-R \quad \text {. }
$$

One may calculate the full width at one half maximum (FWHM) of this distribution to be $\sqrt{2} R$. If $R$ is taken as the range of the proton, $R_{p}$, the predicted opatial resolution of the detector is $3.25 \mathrm{~mm}$.

A more detalled calculation can be made using tabulated electronic stopping data.22 from this data, a specific Lonization distribution $f(r)$ may be calculated numerically. The ionization function $f(r)$ is dezived from a superposition of ionization cqued by the proton and triton reaction products from $\mathrm{He}^{3}(n, p) \mathrm{H}^{3}$. Figure 4 shows the one dimensional spatial resolution function, $D(p)$, under two conditions: curve $h$, uniform conization up to a cut-off range $R_{p}$, the proton range, and curve $B$, specific ionization derlved from Bragg ionization curves. The FWHM of curve $B$ is $1.2 \times R_{p}$ and predicts a physical spatial resolution of $2.76 \mathrm{~mm}$ FWH. This value agrees more closely with our experimental result.

The range of the reaction producte has a small effect on detector efficiency for neutrons. A simple calculation shows that $10 \%$ of the protons and $5 \%$ of the tritons atrike the detector wall before reaching the end of their range. The charge collected from these events is reduced, and depending on the charge threahold for valid events, the effective neutron Bensitivity is al so somewhat reduced.

\section{Electric Fields in the Detector}

We will now compute the electric field and interelectrode capacitance of the various elements of the detector ( $\mathrm{Fig}$. 1b). The field distribution wust be known oo that the charge tranaport in the drift apace, charge multiplication and quantity of charge induced on the cath odes can be known for each event.

The electric field for the configuration shown in
Fig. 1(a), (b) is difficult to calculate exactly. Charpak has given an exact field calculation in two dimensions for the simpler case of a wire grid between two groundud plane electrodes. 24 The exact solution for the configurstion in Ref. (24) is closely approximated by formulae for a plane triode given in Spangenberg. 25 This approximate expression is valid when the interelectrode gap is greater than the wire spacing, and it can be written in the form,

$v \sim q\left[2 \pi L / s-1 n\left\{4 \sin ^{2}\left(\pi_{x} / s\right\rangle+4 \sinh ^{2}(\pi y / s\}\right]\right.$

$$
g \sim \frac{V_{o}}{2[(\pi L / s-\ln \pi d / s)]}
$$

where $q$ is the charge/untt length on the wire

I Is the interelectrode spacing (FIg. 1b)

$s$ is the interwire spacing

$x, y$ are coordinates

$V_{0}$ Is the potential applied to the central wire grid.

From this formula it is clear that the chamber has a region close to the wire in which the field falls as $1 / x,(r<0.1 s)$. Further away the field becomes uniform. becomes:

The capacitance of the central wire grid then

$$
c=e \frac{D^{2}}{2 s} \frac{1}{[(\pi L / s-\ln \pi d / s)]}
$$

where $D$ is the length of one side of a square grid, $c$ is the capacitance. This approximate form satisfies Poisson's equation. However, the equipotentials are only approximately circles at the central grid and straight lines at the ground planes under the conditlons given above. Such an approximation is, however, quite adequate for our purpose. The more complex geametry of this detector, shown In Fig. 1(b), may be analyzed using functions based on the form given in Eq. (4). We have calculated the potential for cathode and anode wires runnting parallel, since crossed wires lead to a three-dimensional problem. Only this half of the chamber is then described in the calculation. Electrical characteristic should not be appreciably different in the other half. We assume the pressure vessel is the reference potential (ground) The cathodes are distance $L_{2}$ f corn the pressure vesael,

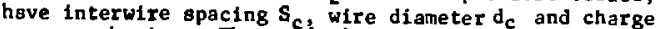
$q_{c}$ on each wire. The anode is at distance $L_{l}$ from the cathode, has wire spacing $s_{a}$, wire diameter $d_{a}$ and charge $7 a$ on each wire; $q_{b}$ is the charge on the ground planes. With these definitions we may write the potential, $v$, as a function of posicion:

$$
\begin{aligned}
V= & -2 \pi q_{b}\left(\frac{y-L_{1}-I_{2}}{S_{c}}\right) \\
& +q_{c}\left\{1 n\left[4 \sinh ^{2}\left(\pi\left(y-L_{1}\right) / s_{c}\right)+4 \sin ^{2}\left(\pi x / s_{c}\right)\right]-2 \pi L_{2} / s_{c}\right\} \\
& +q_{a}\left\{1 n\left[4 \sinh ^{2}\left(\pi y / s_{a}\right)+4 \sin ^{2}\left(\pi x / s_{a}\right)\right]-2 \pi\left(L_{1}+L_{2}\right) / s_{a}\right\} \\
& + \text { Constant }
\end{aligned}
$$

Evaluating Eq. (7) at the surface of the electrodes with the appropriate potentials $v_{a}$, and $v_{c}$, the anode and cathode potentlals, gives rise to two equations in the unknowns, $q_{a}, q_{b}$ and $q_{c}$. The third equation is provided by the substdiary condition that the field outside the chsmber bt constrained to zero. 
Upon saluing this system of equacions for $Q$. these vilues may be substituted into Eq. (7) and the potential as a function of electrode voltages may be calculated. Figure 5 shows a plot of the potential os a function of $y$ far the specific geomecry of our detertor at cwo $x$ vilues, $x=0$ and $x=0.0635 \mathrm{~cm}$ with $v_{p}=1.0$ and $v_{c}$ a $0 . \therefore$. At these voltages, the drift fiolds on either side of the cathode are uniforin. Also, no charge is collected by the cathode although there is a low field region near the cuthode wires assoctated with a soddle point on the potential surface.

The capacitance matrix may be derived from the sys$t e n$ of equations described above. The eleinents of the cupacitance matrix relate the effect on the charge of any electrode caused by changlng the voltage of any other electrode. Thus for the specific geometry under consideration, the cathode rapacitance, with the anode and pressure vessel grounded, $t 9198 \mathrm{pE}$. Thit value agrees to within $10 \%$ of the measured value. Cathode sapacitance is an important parameter in chamber design, as will bo shown below. The optimum position-slgnal processing parrateters are intimately connected to cathode capacicince in terms of count rate and electronic position regblution. By comparision, the capacitance of a parallel plate capacitor of similar dimensions is $275 \mathrm{pF}$. The discrepancy is due to the work needed to move the charge Erom a uniform distribution on the plate to the circular gumetry of the wires. However, provided that the ratio of interwire spacing to wire diameter is less than 100. $t$ parallel plate approxination may be used in most practical cases.

The cathode signal is induced by posicive ions falling through the strong $1 / r$ electric field surraunding the anode wires. Thus, the signal is induced over sevaral wires, and the span of the induced signal is of the arder of the interelectrode gap. Since the cathode in this case is not a solld plane, but rather a linear array of wires, one must ask how much charge is linduced on this cathode wires and how inuch is induced uselessiy on the pressure vessel wall. That which is induced on the swill is not Included in the measurement of the position if an event and hence position resolution suffers. An txacc calculation of this quancity presents formidable mothi:matical difficulties. We are incexested in the field induced by a point charge near the anode wire in the given chariser geometry; such a geometry has few symmetry properties. We can, however, calculate the charge induced on the cathode vs. the pressure vessel by an $1 \pi$ crement of charge spread untformly over the anode. This figure, $n$, is a reasonable estimate of the performance of the accual detector with regard to induced charge. Therefore, $\eta$ may be written as,

$$
\begin{aligned}
r_{1} & =\frac{\Delta q_{b}}{\Delta q_{a}}=\frac{\Delta q_{b} / \Delta v_{a}}{\Delta q_{c} / \Delta v_{a}} \\
& =\frac{c_{b a}}{c_{c a}}
\end{aligned}
$$

where $c_{b a}$ is the box anode capseitance and $c_{c a}$ 1s the cullicide anode capacitance. Tf for our detector is equal Li 11.04 ; negligible charge is lost to pressure vessel sirlls. We have measured this quantity experimentally with neutron induced pulses and found it to be in good agreement. This measurement is taken by comparing the anode signal to the sum of the two cathode signais, 1-n boing the ratio of these two quantities.

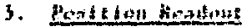

\section{S.1 Shanal Peoteosin:}

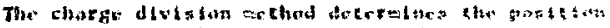

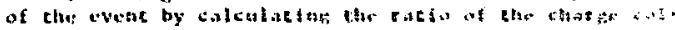

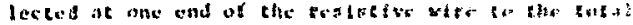

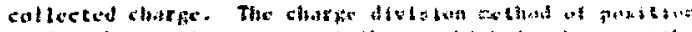

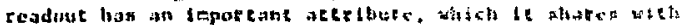

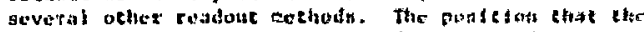

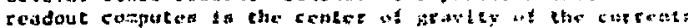
induced on che cachodu wites. Hence we have lie cathats:-

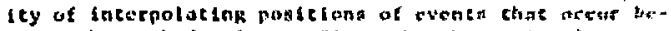

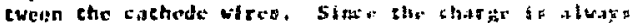

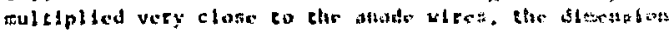

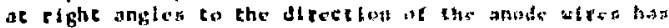

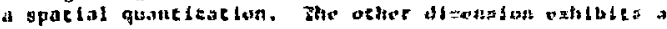

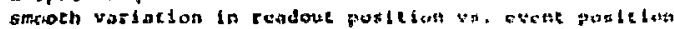
dur to the interpolating nature of the teadsut.

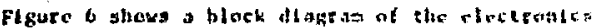

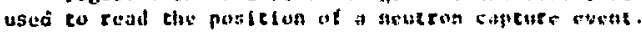

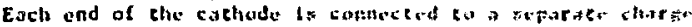

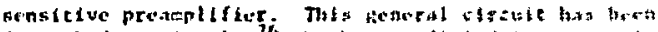

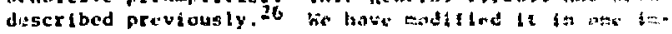

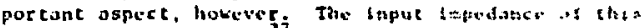
circult is shumet to be $i$

$$
R_{1 n} \cdot \frac{1}{t=} \frac{c_{n}}{c_{l}}
$$

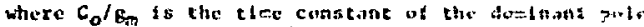
in the open loop galn of the predeplicter and $C_{\text {a }}$ tise

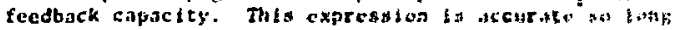

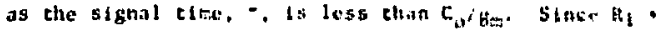

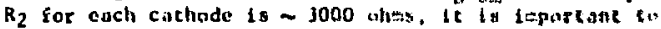
keep the isput resistanes of the preatepllfier pondl. otherwise the position sensitiugty if clie readost in

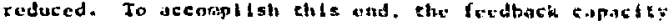
$C_{f}$ was chosen to be 50 pf and the fecthack restacer to be : megohm. Thuse volues glues the desired jo was

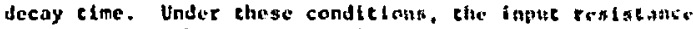
is measured to be approximately so abes. The eurgets wave form from the esthode is proportintsl to $\left(1+\mathrm{C} / \mathrm{g}_{2},\right)^{+1}$ when $t_{0}$ is a parameter dependent on app!lad yiltatis. positive ion mobility. and chumber peveretry. 28 Jiws the voltage output of the proantifler is proportonol to $\ln \left(1+t / t_{0}\right)$, the Integral of the curreat, l.... sharss. These are waveforms orlsing from lontzation terckgi ia the gas of zero poch tengeh. For luntintion pitchs of finlte excege (the case for protons and ertton in tis reaction $\left.\mathrm{He}^{3}(n, p) H^{3}\right)$, the waveforms will be further smeared out in eime. The lower linat of side prejaplifter banduldeh further alters the waveforbs, mokling the decay with a time constant of approximately sc wace. Henes. rather thas specify $t_{0}$, the risetime of the preatiofier output pulse is used to characterize the wivelorss. For our configuration, the rtsctime $(10 \%, 0$ 907, of the preamp output waveform) is measured to bet 0.5 ssec

Unfortunately, the current autput from cich cationdo is sufficienty smoll that the noise from various disafpotive componente in the electronics can causa afparent spacial resolution effects compirable to thase caused by the finite path length of the products in tien neutron sapture reaction. Of these somrces, the dominant nolse component is generated by the resdout wire itself. Thus, the optimlzation of circult parumeters Jgalnat these noise cffects is necessary. An extensive anilysts of this subject has been presented in Ret. (27). from 
whet re will quace refules.

7to eutput of the chargo-senale tue preseplifiors is furcher shaped and anplitied by cwo delay line clipped

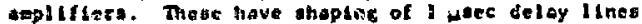
tollowas by intagration with a teico conetone of .25 usec. This sheplng enables che posteton docereination to ve made based on virtually all the charge fros an ovont inditerd on the cachodes. Alehough posicton I lnearity does not sucter 16 alt the charge il not collocted, postzion redolution tera. On the other hand, if the pesureaont ts is axtended con tons, the posteton resolutien will also vorien sup to noler as doserlbed betak. Hence. the

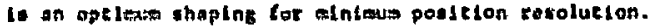

For tha hapher wave chosen, way calculete the posteron reontuction oxpected an the besis of electronle molse aloat. the whin chis noter contribuclon to redoluclon to be alenificontly leas than that caused by the charged parelcle path tengthe fros the lth renction.

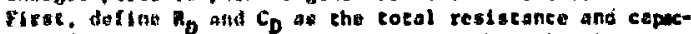
ey of the cathade. Fos tio with of the delay IIfr

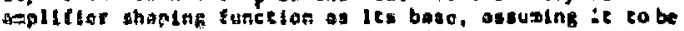

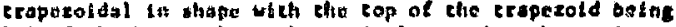

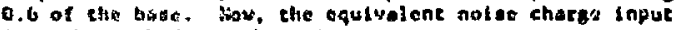
lnce sht caethends can be uriteren.

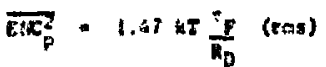

and the rolotite fletionic reaclution of the sathode is

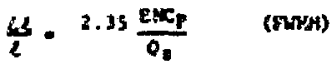

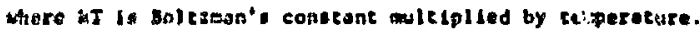
Thus in our caso tD $=1000$ ?, $C_{D}=200 \mathrm{pF}$. "F *

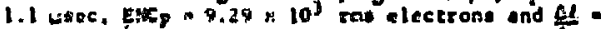

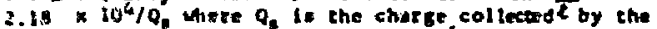
cathode. We expuec to coldect 5 a $10^{6}$ electronic charges an esith cettede. Theretore, 45 -0.4j7z. Ualne luaped

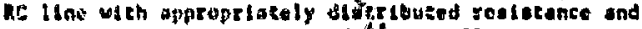
capacieance. to have reasured $f \circ-0,47 x$, confirelins cho stutation. This posict ort resolution is equivalent to appromiately I to in epatilal resolution ovar $17 \mathrm{~cm}$. since thy partcle range to expected to yield a resolu. tlon tunction of $-1 \mathrm{~m}$, the Inteiel criterion loz the

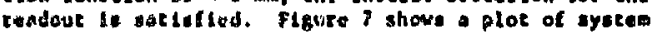
pollelon oucpue va. Injected charge postedan on at RC ine with lincorly diseritiuted resierences. Thie ac lint oleulares the parametern masured in the detector. The non-lingaricy of chil graph is leas than 0.37. a* inceratined by fitcing the dece to a quadrocic function, whers non-lireartey is defined ac one half the raclo of tho quadraste tere to tho total eqacured postelon as the taxteus abclasa. In the next seftion, we shall show iteillar reatilte tahen from actual neutron data.

The above andyels defines the batc performance of the syatem. Tie remalnder of the clreulexy ahown in the block diagran (Fig. 6) acrves basically to reallte the division function. The unipolor outputs of the linear amplifiers ere added in one chennel to give the tocal chlisgo collested from the cathode. Thie wis eignal ind the chnorallixed posizlou lignel ore applied to the IImest Inpucs of a palt of I Inear gates and etretehers. Thase Iinear gaces axe serobed by a lignal derived from the sum of the hipolat oticpute of the delay line clippod atoplifiers. Thie oun is procesed chrough a tiolng single chennel andyecr that provides energy diserimination ageinat notae and poselble gama ray contaminetion of the charged pareiclo enurgy epectem. It 18 chis output which aerobes both the linear gates and the divider. the output of which is the measured posicion signal.

Eech cothodo has electronles Identical to thist daecribed obove. In addicion. a cime colncidence is requited between the ciming single channel outputs of each cathode to accept a valid event. The analogue output algnele are converted in scperace anologue-to. digital converters and the diglcel resule is stoped in 12,000 aemory locations of wediun size digital computer. For luteher analyals, che results are transferred to magnatc tupe and processed off-linc.

\subsection{Analorue DIylder Clrcuiery}

The complete clacuic diagram of the analogue divider is show In Fige. 8 and 9. The divider ls based on logartehmic converation of the two input varlables, and on the exponentiel conversion of the difterence of the swo lotarithas. The logarielunic-exponential conversions are partorned using the exponentiol characteristics of semiconductor junetions. Thlo solutirin wos chosen becal sw of thherently good accuracy over o large dynamic rong:, and ince the developaent of fost logarithmic converter circule 29 ade fase conversion pusalble. It can be shown chat the temperature dependence of such a divider circuit can be reduced to term $(Y / X) A T_{l} / T_{e}$, where $I_{l}$ and $T_{c}$ arc absolute ceteperatures of the funcelons uged for logartithalc and exponential conversion, and $A$ is the gain of the

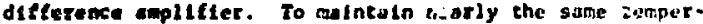
atura for the two logarithale converters and for the exponentsel converter on incegrated monolichic mulciple eranalstor ctrcult weo used, and the maxteum power dissipation wat kapt at a few alilituats. Fast iogarithmic convertion was discuseod in detall in Ref. 29. Inputs to logarlehale converters are ds coupled. A small adfustable correction is proulded for the residual enitent rosetance in both the logartehalc and exponential circults. In the toraer, a linear tere (a conocant fraction of the Inpue) in subtracted from the logarithmle output. In the exponential circuite. I Inear ecrit (constane fraction of the output) is added to the drive via the critecr.

The exponential converter is ac coupled at the input, and it incorporates a baseline restorer (tronsistors 16 to 22). This solution was chosen to ethleve dc stablikty. This exponential converter usa developed from a clrcule by Goulding. 30 the galn $A$ for the difference of logerithme should be unity. (Otherwise the output is an exponential function of the ratio.) The output of the divider to exrobed during the flat cop portion of the input eignalt, to evold large signals when the denominator I. sanll or zero.

The etreust can be adjusted to an accuracy of clic ratlo of 0.22 over dynanle range of 20 to 1 . The division to perfored in soo nace.

\section{Besulis}

The chaber, es described in the previaus ecctions. has betn cested for a varicty of parametors that indicate ite parformance under real expertmental conditions. Arong these paracetere are epatal resolution, spatiol non. lineerity, apotial non-und foralty In efficiency, woll effect, beckground garmanray sensitivity, detection of ILciency, event neolutis tlme and cvent processing time. A submary of thio information along with the physical chamber characteristics is presented in Table 11.

Pigure 10 show the pulse height opectrum derived 
from pulses summed from the two ends of the cathode, as shown in the glestronic block diagram (Fig. 6). The other calhude produces the same spectrum. The pulse height in this spectrum is proportional to the total charge collected by the anode and, hence, to the tetal energy depouited In the detector by the reaction products from $\mathrm{He}^{3}(\mathrm{n}, \mathrm{p}) \mathrm{H}^{3}$, $(\mathrm{Q}=764 \mathrm{keV})$.

The energy resolution displayed in the energy opectrum (Fig. 10) 10 worse than one usually sees in single wire He ${ }^{3}$ filled neutron detectors. At lower voltages, and hence lower gains, the spectrum shape is comparable to thet ubtained in ReEs. (6-9) and the energy resolution is similur. However, as the gain of the chamber is increased, the spectrum shape deteriorates to that shown in Fig. 10. It is reasonable to ascribe the degrading of the energy spectrum to apace charge effects. ${ }^{3}$ Difrerent track orientations of the reaction products yield different appurent tharge gains due to charge densicy effects around the anode wirc. The cholce of operating point and gain wis made on the basis of spatlal resolution desired vs. tolerable gama-ray background. At high galns the energy resolution of the neutron peak deterlotates. Therefore, :o remain at the same neutron efficiency une must accept: mure ganma background. All tests reported in th1s section were performed with discritninators set at $370 \mathrm{keV}$, Fig. (0).

It Is difficult to define gamia-ray sensitivity in the typical reactor environment oince many gamma-rays of different energy are produced. However, in the environmulit in which this detector operated, (BNL. HFBR) the gumma-ray background is 5 counts/sec with the primary beam on and stopped on boron-poly. A more systematic definition of gama-ray sensitivity was made by placing a $1 \mathrm{mCl} \mathrm{Co} \mathrm{Co}^{6}$ source $60 \mathrm{~cm}$ from the face of the detector, oriented at normal incidence. With the threshold at $370 \mathrm{keV}$, the gamma sensitlvity $132.7 \times 10^{-6}$ gamas detected/incldent gatuma.

The neutron detection efficiency of the chamber has buen measured by intercepting the incident neutron beam $\left(? .=2.8 \%\right.$ with $\mathrm{g} 95 \%$ efficient $\mathrm{BE}_{3}$ detector. The ratio of the event rate in the different detectors gives the detection eff 1 ciency of the He 3 position-sensitive detector hie meisure this number to be $70 \%$. Calculation (FIg. 3) yiulds in efficiency of $32 \%$ for this wavelength. The major part of the discrepancy between these values is inost likely due to wall ef kect. This effect is evident in Fig. 10 in the slight bump to the left of the main pesk. a feature caused by the non-uniform energy loss of those tritons thot strike the chamber wall. The energy of this bump equals the toral Q-idulue minus the triton energy ( $573 \mathrm{keV})$. The proton wall eifect is partlally ubscurced by the rising garma background, otherwise, a sinilar feature would occur at ini keV. 21

W. now describe the meaturement of spatial resolution $v s$. charge collected ot the detectur anode. The electronic cintribution to the spatial resolution may be separated frith the physical contribution by varying the detector anide voltages. We have performed this measuremene and results are shown In Fig. I1. The abcissa is the voltage be Lween cathode and anode, which determines charge gain. The crdinate is the FuH spatial resolution of the detectir parallel to the anode wires. Above 2800 volts the spatill resolution saturates due to physical chamber parimeters at $2.5 \pm 0.1$ mro. The higher voltages lead to problemg with background rejection as described above. Hence, the detector is operated at approximately 2800 vilts and a spatial resolution of $3.1 \neq 0.1 \mathrm{~mm}$.

The contribution to the spatial resolution from the physical puth length of the reaction products is $2.5 \pm$ $0.1 \mathrm{~mm}$. In Section 3, we have calculated the physical range to be $2.76 \mathrm{~mm}$ using tabulated range and energy loss data. This agreement is quite close constdering the difficulties in calculating specific ionization at low values of proton and triton energy.

We have measured two quantities affecting count rate capacity of this detector, namely event resolving time and event processing time. The former may be defined as the time in which the detector is sensitive to event pileup. Such pileup can lead to false position calculations. The latter refers to the time in which the system is insensitive to incoming data. Events occurring in this time period are lost; hovever, the validity of the event being analyzed is not compromised. The measured values are, at present, 1 usec for event resolving tire and $3 \mu \mathrm{sec}$ for event processing time, We are operating In a conservative manner at present, and a factor of two reduction in these times is wholly feasible.

Figure 12 shows a sweep of the primary neutron beam across the detector in a direction parallel to the anode wires. Data were taken every $1.46 \mathrm{~cm}$ across the detector face at the inidline of the detector. Also shown on the same figure is true position of the beam vs. measured posttion. There is a residual nonlinearity in the measurement of true position vs. measured position. This error is approximately $1 \%$ of full scale or $0.17 \mathrm{~cm}$ and may easily be described by a simple quadratic function.

The detection efficiency is uniform to within $3 \%$ across the entrance window of the detector. Any effect here 15 caused by gain variations across the detector, which in effect change the pulse height threshold seting as a function of position. We have observed this effect by gating a multichannel analyzer on spatially distinct areas of the detector. Regions of increased gain correspond to regions of increased efficiency.

Elgure 13 is a contour plot of a complete twodimengional detector scan with the primary neutron beam. A well collimated neutron beam was swept across the detector in a regular rectilinear pattern. Each contour represents approximately $20 \%$ of the full peak height. The increment along the $x$-axis is $1.46 \mathrm{~cm}$ and along the $y$-axis $2.54 \mathrm{~cm}$. Each line in $y$, upon integrating over the peak in the y directicn, yields a plot similar to that shown in Fig. 11. From this ilgure we may deduce that there is no interaction between coordinates in position deterinination which would possibly give rise to "barrel" or "pincushion" distortion. Thus, the two axes are completely independent. This fact facilitates any correction needed for the residual non-linearity left in the readout system. Each axis may thus be corrected independently irom the other.

Figure 14 shows scattering data (intenstey vs. angle 26) from retinal rods, the light transducing system of the eye. Dellcate samples such as these are easily damaged by radiation and ambient conditions. The maximum neutron exposure time for these samplesi in axygenated Ringet solution is about eight hours. Conventional single counter systems, which scon in angle $2 \mathrm{~s}$ point by point, do not have the sensitivity to adequately measure the neutron diffraction pattern from such samples. The bottom three traces show the accumulated intensity profile of ten frog retinas scanned by a conventional system. 1 The second and third traces represent data collected in the oame fashion as the bottom one, but using an improved surgical and sample mourting technique. The top trace represents data coblected from two retinas with the two-dimensional detector, 
using the improved mounting techntque and a smaller sample. This data extends to larger angles, permitting analyo 8 of the membrane structures to the desired resolution. 32 The use of a much smaller sample regults in better data with considerably less ef fort.

\section{Acknowledgenents}

We wish to acknowledge the assigtance of $R$. Dillingham and J. Gatz in the fabrication of this detector. C. Nawrock 1 and $\mathrm{J}$. Trebing aided In 1 ts asoembly, and $\mathrm{E}$. Caruso helped with teating and checkout. B, Gaer aided in the preparation of this manuscript.

\section{Table I}

Neucron-Charged Particle Reactions Sultable for Thermal Yeutron Detection

$$
\begin{aligned}
& \text { Reaction Thermal } \\
& \text { Q-Value Crose Section } \\
& \text { a) } \mathrm{B}^{10}+\mathrm{n} \longrightarrow \mathrm{Li}^{7}+\alpha+2.79 \mathrm{MeV}(6.1 \%) \\
& L_{1} 1^{7}+a+2.31 \mathrm{MeV}(93.9 \%) \quad 3840 \pm 11 \mathrm{~b} \\
& L j^{7}+\gamma+0.478 \mathrm{MeV} \\
& \text { b) } \quad 21^{6}+n \rightarrow H^{3}+a+4.786 \mathrm{MeV} \quad 936 \pm 6 b \\
& \text { c) } \quad \mathrm{He}^{3}+\mathrm{n}+\mathrm{H}^{3}+\mathrm{p}+0.764 \mathrm{MeV} \quad 5327 \pm 10 \mathrm{~b}
\end{aligned}
$$

\section{Table II}

Two-Dimenstonal Position-Sensitive Detector

1. Neutron detection efficlency at

2.8 \& wavelength.

2. Position resolution at $v_{a}-v_{c}=2800$ volts .... $3.1 \mathrm{~mm}$

3. Positional uniformity of detection efficiency... 3\%

4. Integral linearity $\ldots \ldots \ldots \ldots \ldots \ldots \ldots \ldots \ldots \ldots$ 1\%

5. Differential Iinearity....... 0.1\%/\% of full scale

6. Event resolving time................. I Hoec

7. Event processing time................. 3 usec

8. Gamma-ray sengitivity $\left(60^{60}\right): 2.7 \times 10^{-6} \gamma$-detected/ incldent-y

9. Sensictue area $\ldots \ldots \ldots \ldots \ldots \ldots \ldots \ldots .18 \mathrm{~cm} \times 16 \mathrm{~cm}$

10. Ges filling composition 6 atmos. $\mathrm{He}^{3}$ (absolute prissure)

4 atmos. A

\section{References}

1. B. P. Schoenborn and A. Nunes, Annual Raview of Biophysics and Bioengineering, $1,529(1.972)$.

2. B. Rosal and H. Staub, Iontzation Chambers and Counters, McGraw-Hi11, New York (1949).

3. D. H. Hilkinson, Ionization Chambers and Counters, Cambridge Untv. Press, Cambridge (1950).

4. S. A. Korff, Electron and Nuclear Counters, Van Nostrand, New York (1946).

5. X. H. Beckurta and K. Wirtz, Neutron Physics, Springer-Verlag, Berlin (1964).

6. R. Batchelor, R. Aves, and T. H. R. Skyrme, Rev. Sci. Instr., 26, 1037 (1955).

7. A. R. Sayres, K. W. Jones, and C. S. Wu, Phys. Rev., $122,1853(1961)$

8. W. R. Millo, et al., Rev. Sc1, Instr, 33, 866(1962).

9. v. E. Krohn, Jr., Rev. Sc1. Instr., 35, 853 (1964).

10. R. Grove, I. Ko, B. Keskovar and V. Perez-Mendez, Nucl. Instr. Meth, 99, 381 (1970).

11. D. M. Lee, S. E. Sobottka and H. A. Thiessen, Hucl. Instr. \& Meth. 104, 179(1972).

12. J. R. Gilland and J. G. Eming, Hucl. Instz, \& Yeth. 104, $241(1972)$.

13. K. Louterjung, et al., Nucl. Instr. \& Meth. $\underline{22}$, $117(1963)$.

14. W. R. Kuhlmann, et al., Nucl. Instr. \& Meth. 40 , $118(1966)$.

15. C. Kalbitzer and W. Melzer, Nucl, Instr. Meth. 56. 301 (1967).

16. R. B. Owen and M, L. Awcock, IEEE Tranf. Nucl. Sci. SS-15, 290 (1968).

17. C. J. Borkouskt and M. K. Kopp, Rev. ScI. 1nstr. 39, 1515 (1968).

18. C. J. Borkowsk1 and M. K. Kopp, 1EEE Trans. Nuc1. ScI. N-17, 340(1970).

19. C. J. Borkowski and M. K. Kopp, IEEE Trans. Nucl. Sct., NS-19, $161(1972)$.

20. Hoim Zaklad, UCRL-20690 (1971).

21. 8. Shelev, 2. Fishelson and J. M. Cuttler, Nucl. Instr. \& Meth. 71, 292 (1969).

22, 1. C. Northcliffe and R. F. Schilling, Nuc1. Data, 7. $233(1970)$.

23. R. D. Evans, The Atomic Nucleus, McGraw-H(11, New York (1955). 
24. G. Charpak, Ann, Rev. Nucl, Se1., 20, 195(1970).

25. K. Spangenberg, Vacuum Tubes, NcGraw-Hill, New York (1948).

26. V. Radeka, Proc. Intern. Symp. Nucl. Electronics, 1. 46-1, Versallles (1968).

27. V. Radeka, IEEE Trans. Nuct. Sc1., NS-21, S1 (1974).

38. G. R. RIcher, Jr. and J. J. Gomez, Rev. ScI. Instr. 49. $227(2969)$.

29. V. Radeka, Nucl. Instr. \& Meth, 113, 401 (1973).

30. F. S. Goulding, D. A. Landis, J. Cerny, III, and R. H. Peh1, IEEE Trans, Nucl. Sc1., NS-11, 388 (1964).

31. G. C. Kanna, et a1., Phys. Rev. 75, 985 (1949).

12. M. Reager, et al., J. Med. Biol. (In press). 


\section{FIGURE CAPTIONS}

Fig. 1 a) Schematic diagram of multiwire proportional chamber geometry.

b) Schematic diagram showing parameters for the electric field calculation.

Fig. 2. Calculated detector efficiency vs. neutron wavelength for a gas filling of $40 \%$ argon and $60 \% \mathrm{He}^{3}$ by volume at 10 atmospheres.

Fig. 3. Detection efficiency of $4 \AA$ neutrons vs. gas composition at 10 atmospheres pressure (curve A) and proton range vs. gas composition at 10 atmospheres pressure for two gases, argon and krypton, (curves $B$ and $C$ ).

Fig. 4. One-dimensional spatial resolution function, $D(p)$, under two conditions: A, uniform ionization to a cutoff range $R_{p}$, the proton range and $B$, specific ionization derived from Bragg ionization curves.

Fig. 5. Electric potential as a function of $y$ for the specific geometry of our detector at two $x$-values, $x=0$ and $x=0.0635 \mathrm{~cm}$ with $v_{a}=1.0$ and $v_{c}=0.4$

Fig. 6. Block diagram of the electronics used to read the position of a neutron capture event. Labeled values are as follows: $R_{a}=100 \mathrm{M}$, $C_{a}=0.015 \mu \mathrm{F}, C_{i}=0.01 \mu F, C_{f}=50 \mathrm{pF}, R_{f}=1 \mathrm{M}, v_{c}$ and $v_{a}$ are cathode and anode voltages.

Fig. 7. Position output vs. injected charge position on an RC line with linearly distributed resistances.

Fig. 8. Fast analog divider based on logarithmic-exponential conversion. Fig. 9. Auxilliary circuits for the analog divider in Fig. 8 (linear gate, output stage and strobe control). 


\section{FIGURE CAPTIONS (Cont'd.)}

Fig. 10. Pulse height spectrum derived from pulses summed from each of the two ends of the detector cathode.

Fig. 11. Measured position resolution (FWHM) vs. applied cathode to anode potential, $\mathrm{v}_{\mathrm{a}}-\mathrm{v}_{\mathrm{c}}$.

Fig. 12. Sweep of the primary neutron beam across the detector in a direction parallel to the anode wire. Data were taken every $1.46 \mathrm{~cm}$ across the detector face at the midline of the detector.

Fig. 13. Contour plot of a complete two-dimensional detector scan with the primary neutron beam.

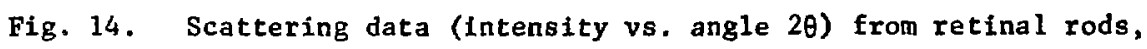
the light transducing system of the eye: the bottom three traces are taken with conventional techniques (see text). The top trace is taken using the position-sensitive neutron detector. 

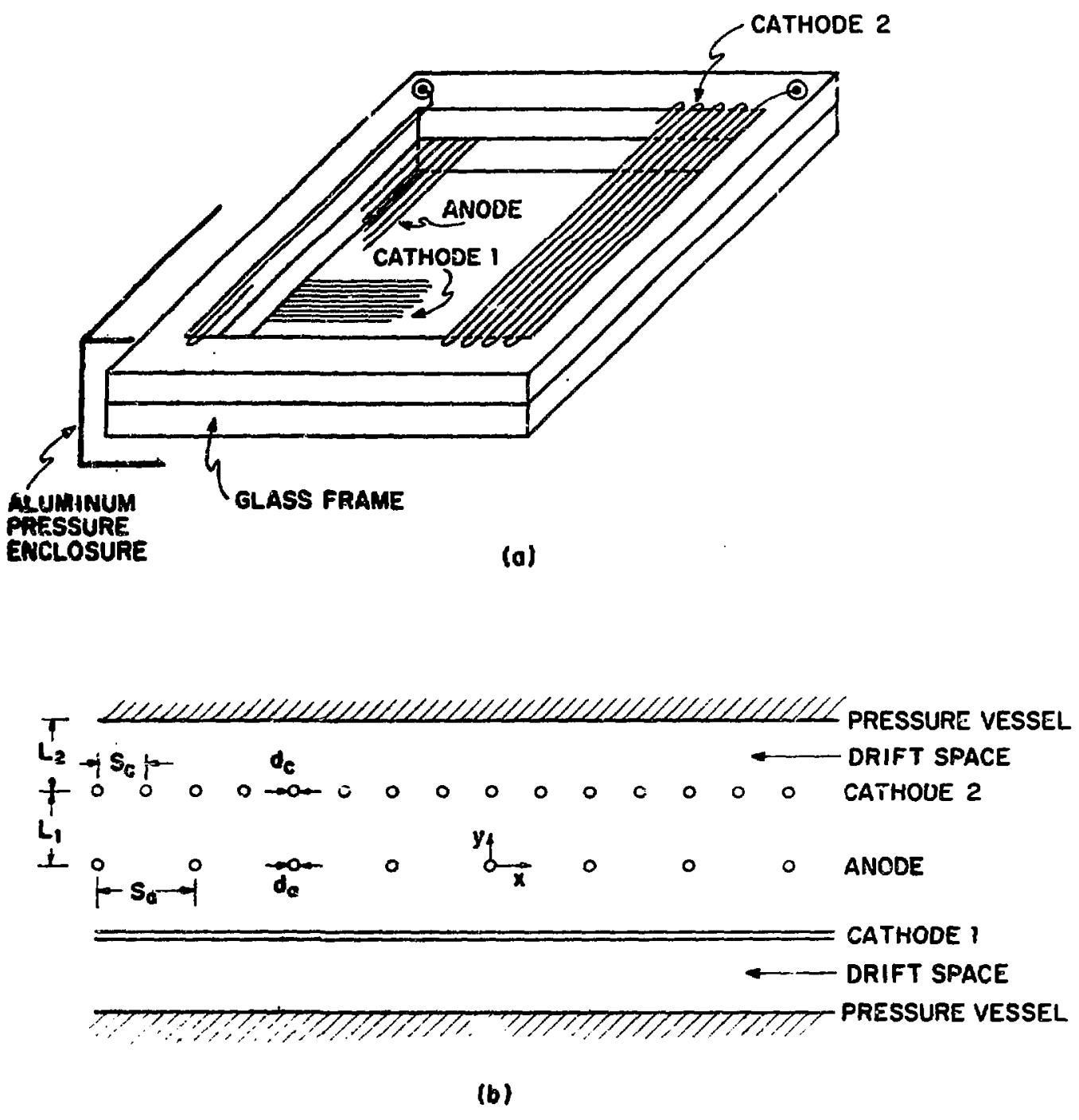


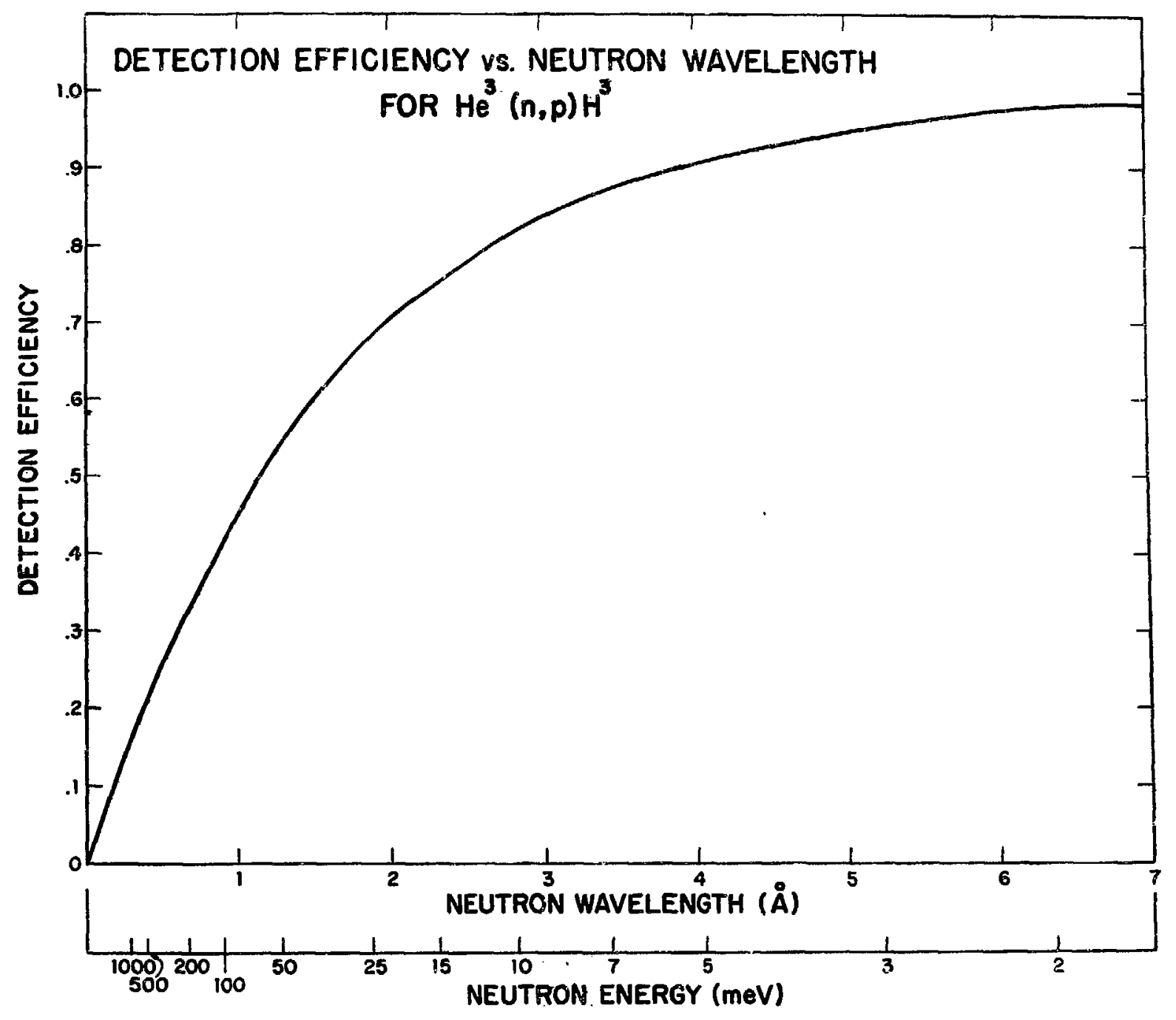

FIGURE 2 


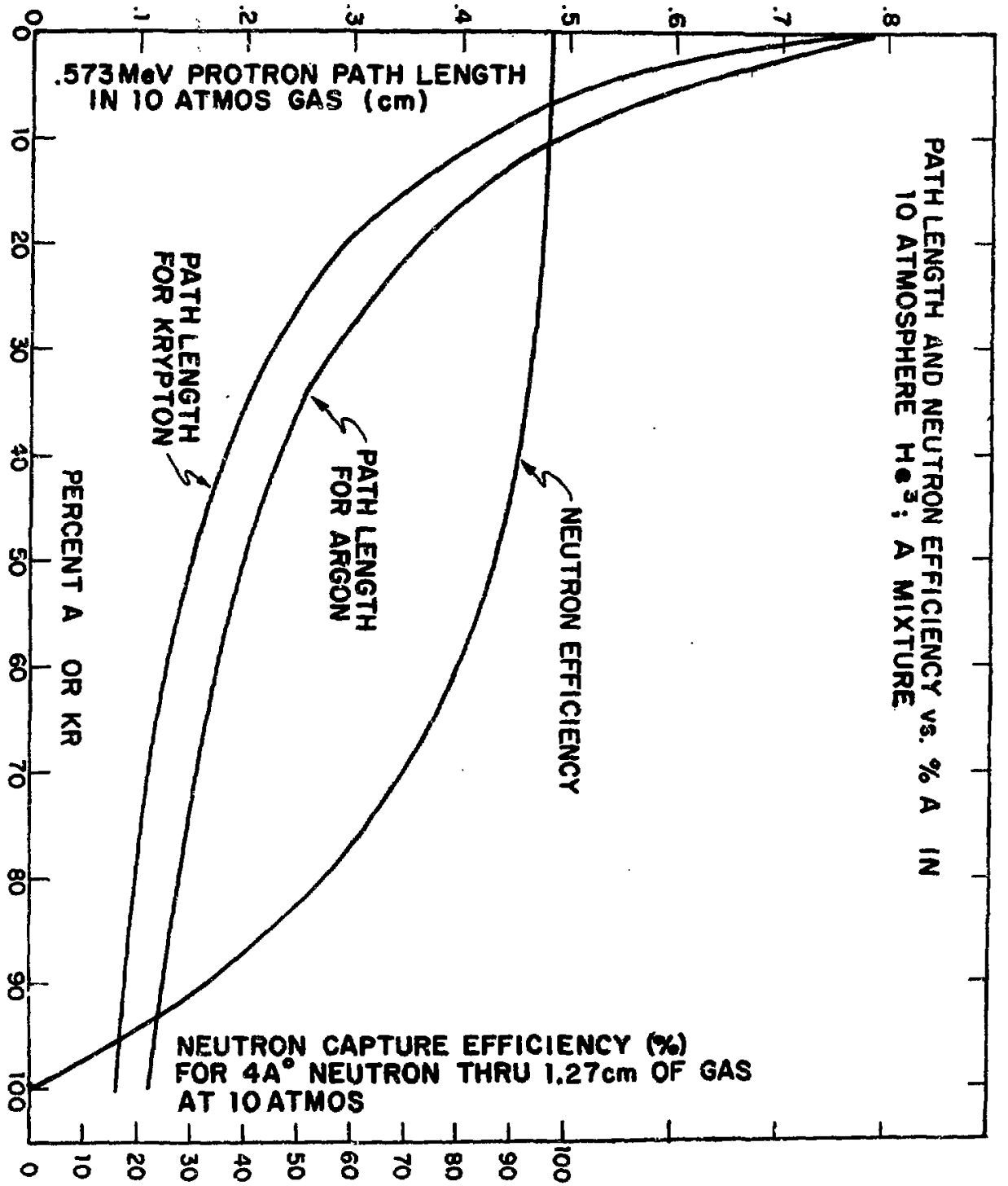




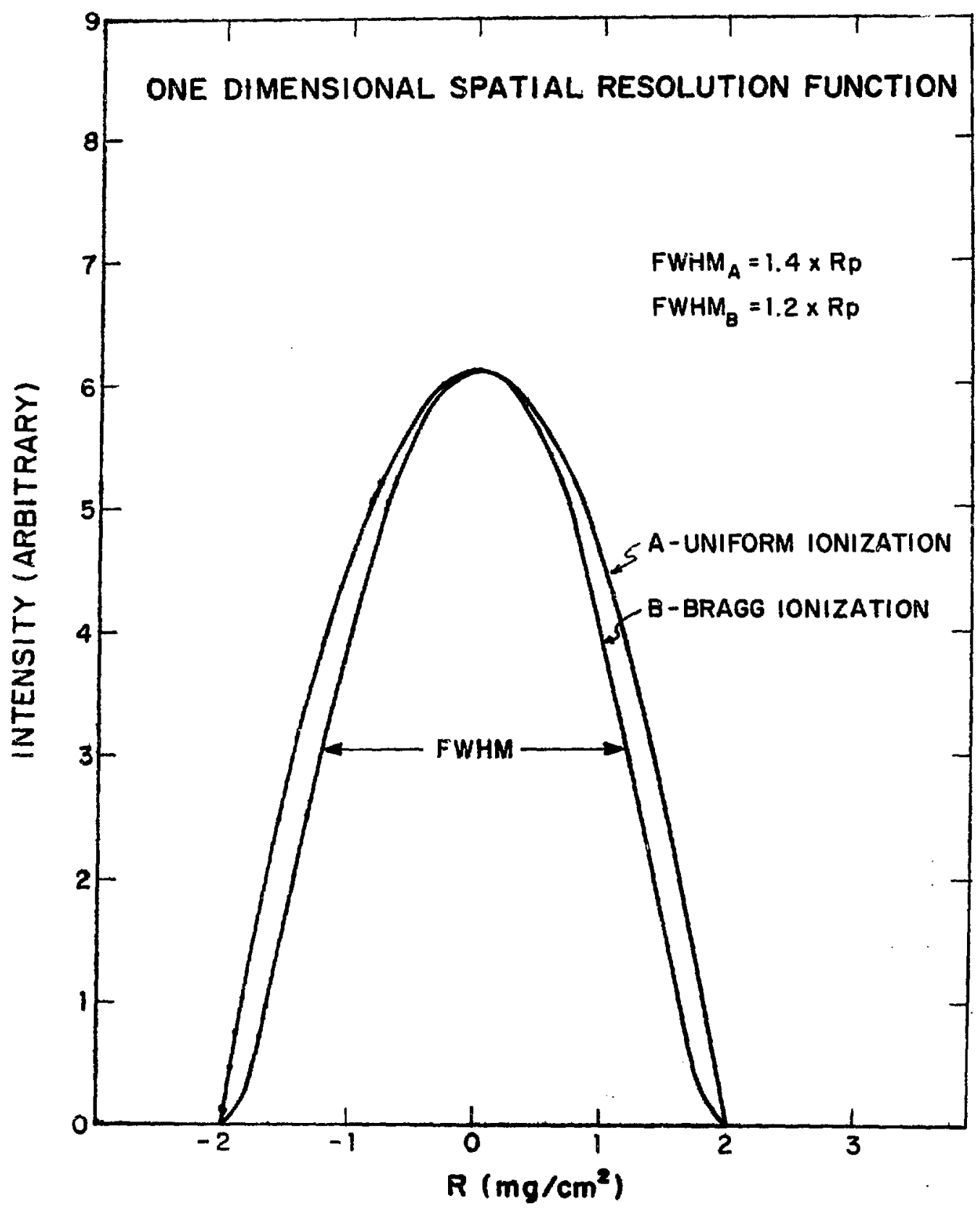

FIGURE 4 


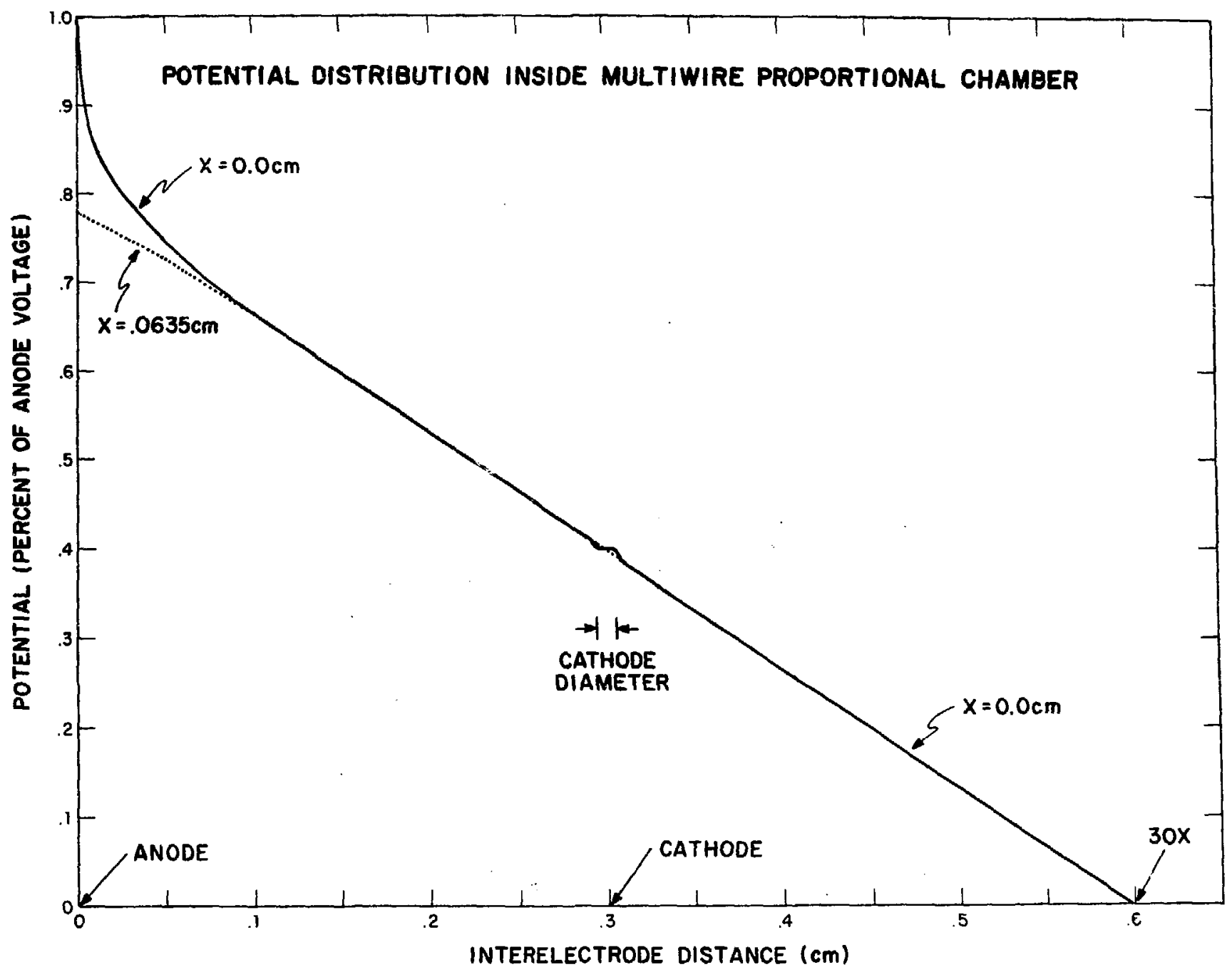

FIGURE 5 


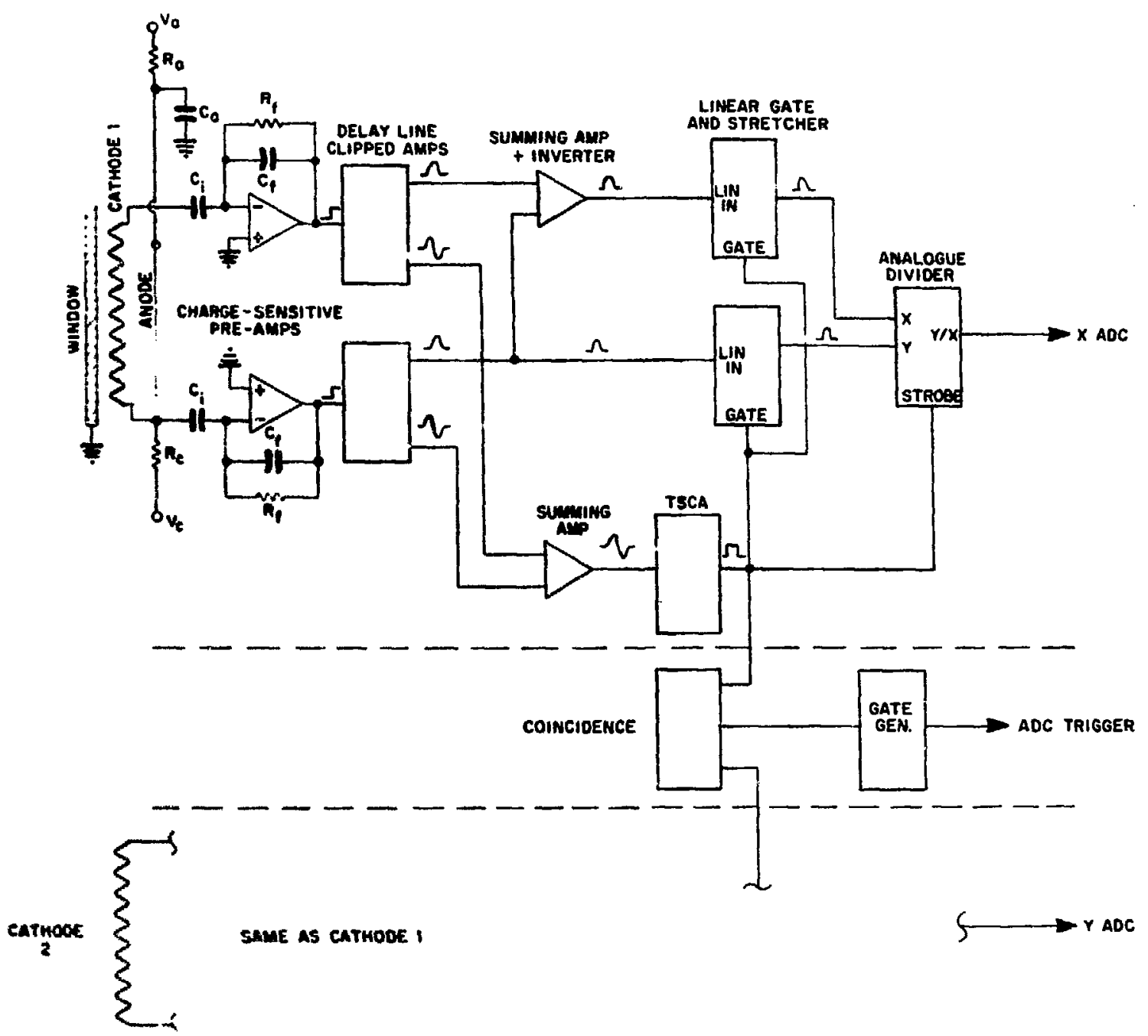

FIGURE 6 


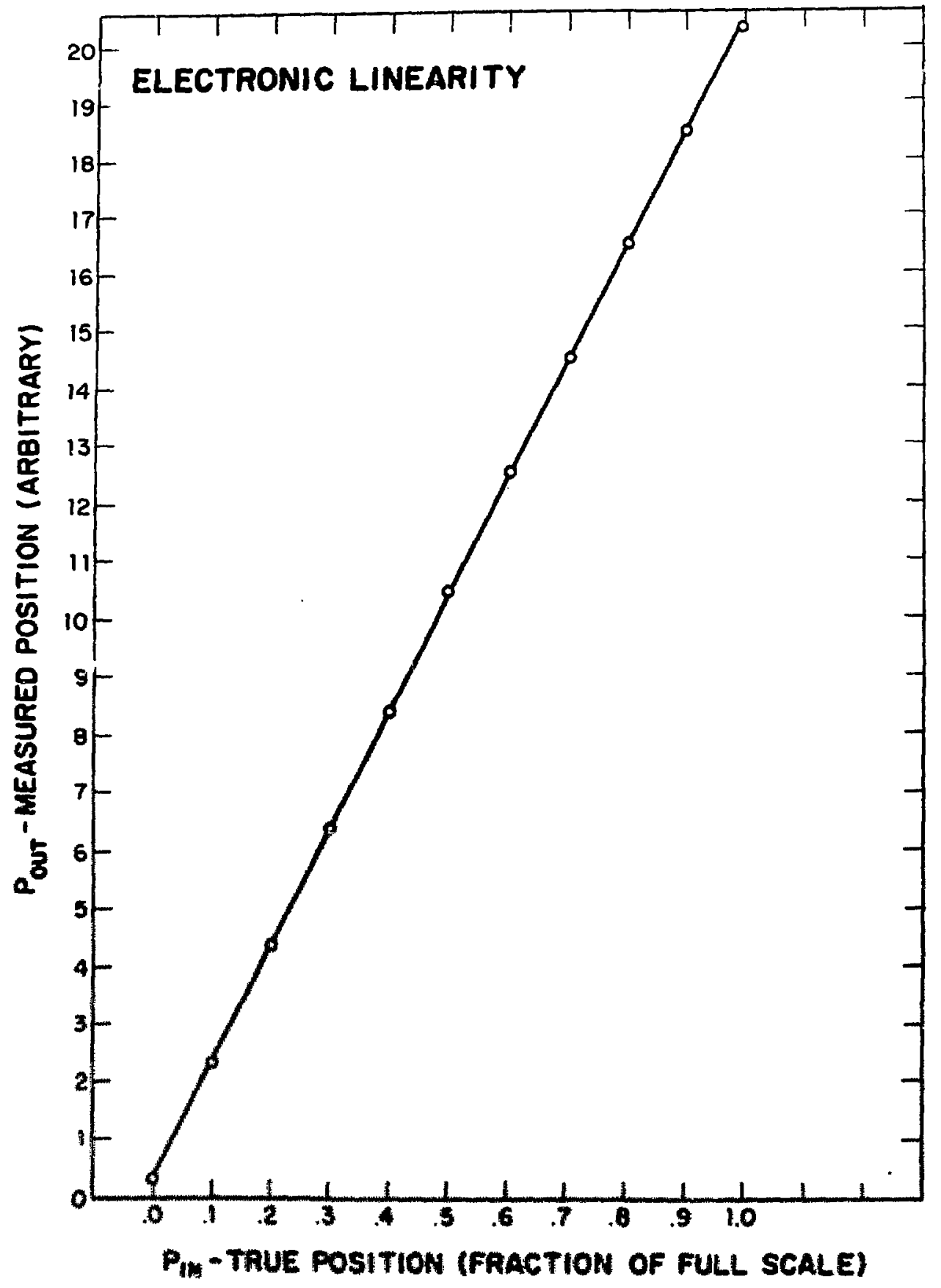

nouk 7 


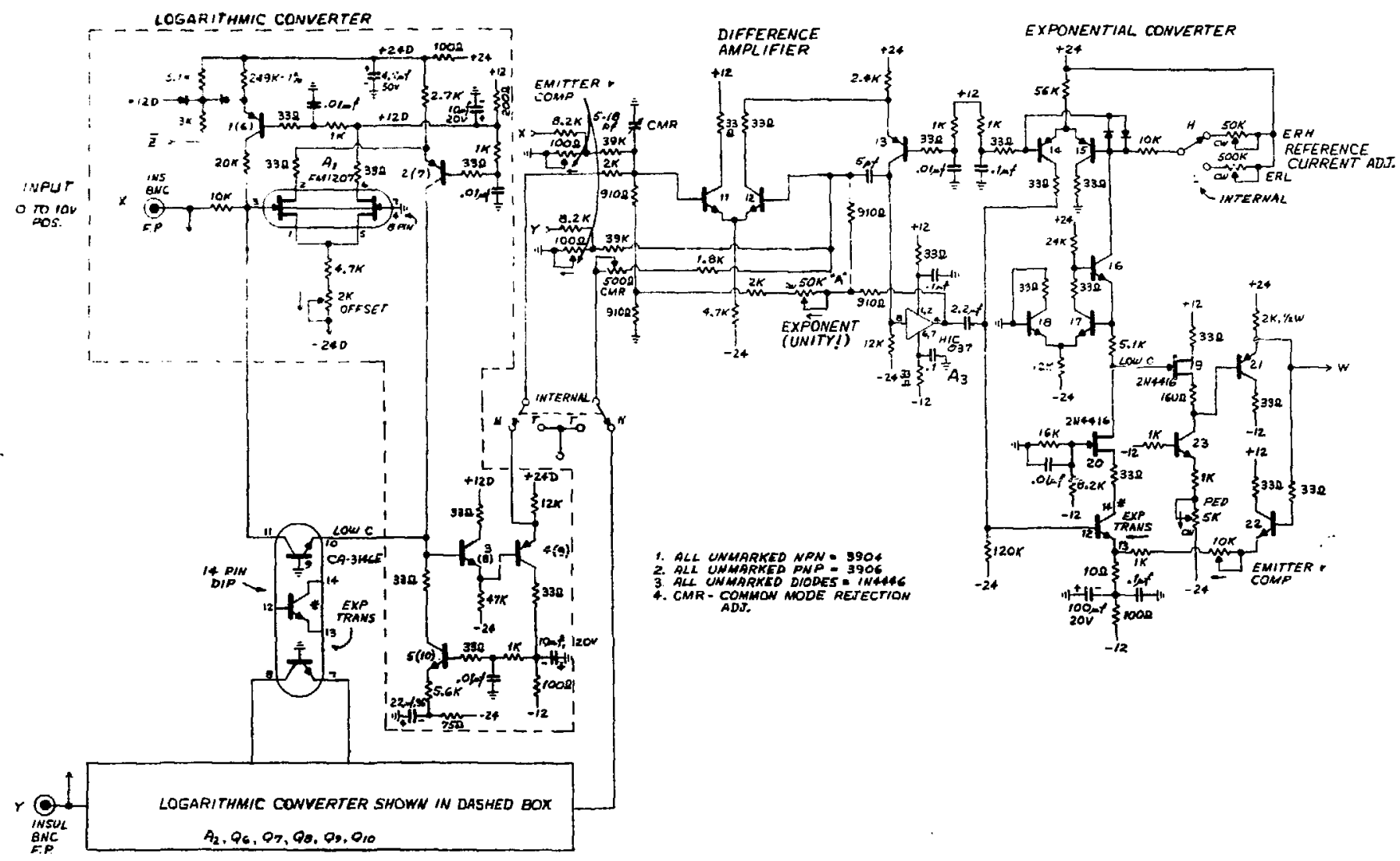




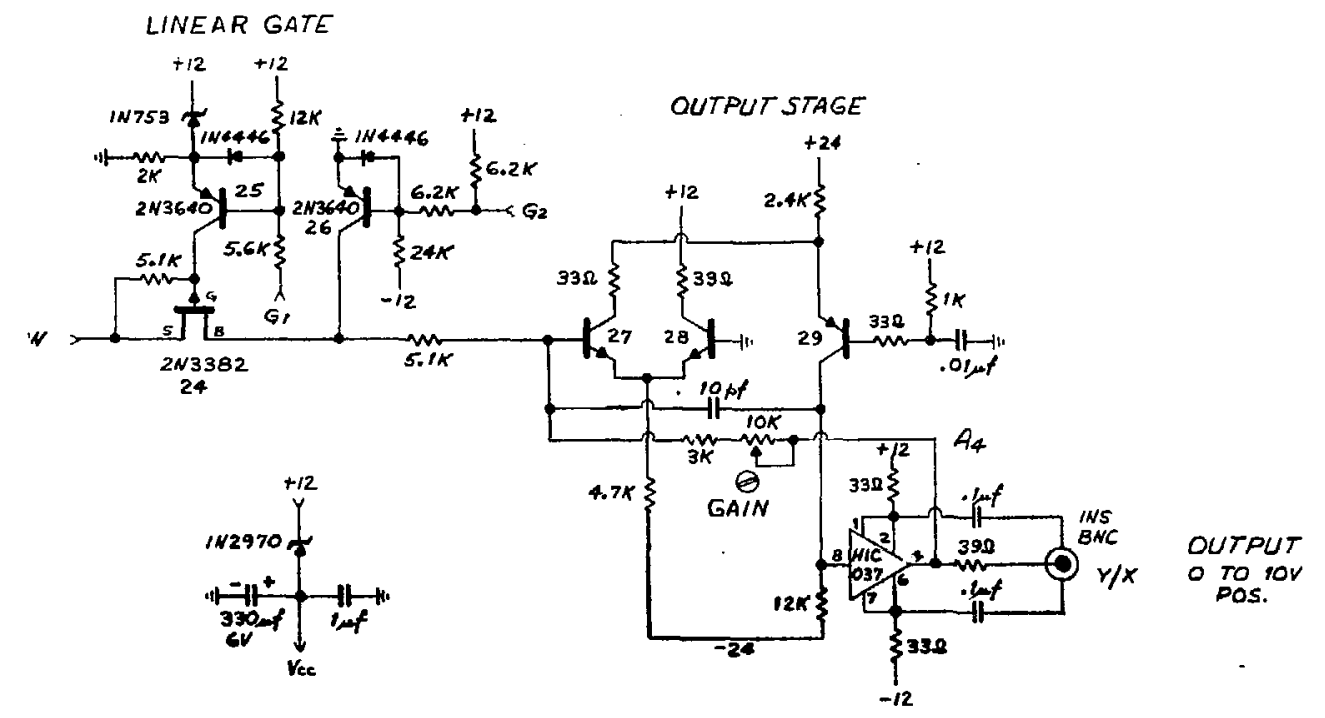

1. ALL UNMARKED NPN $=3904$

3. ALL UNAARKED DIODES $=1 N 444$

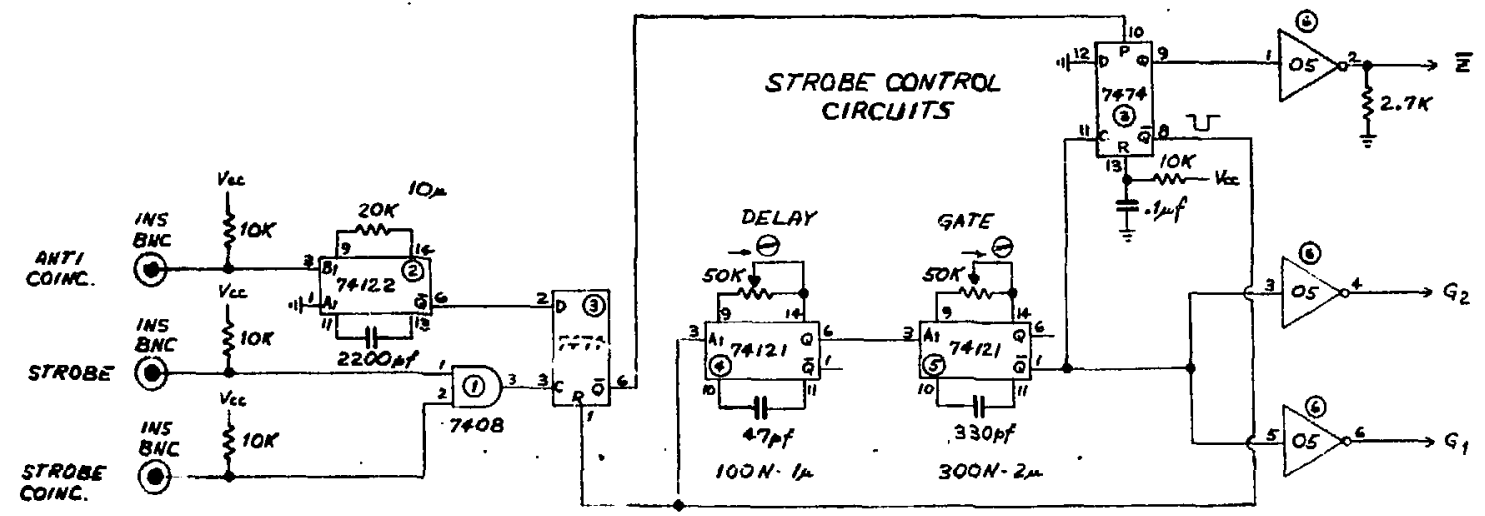

FIGURE 9 


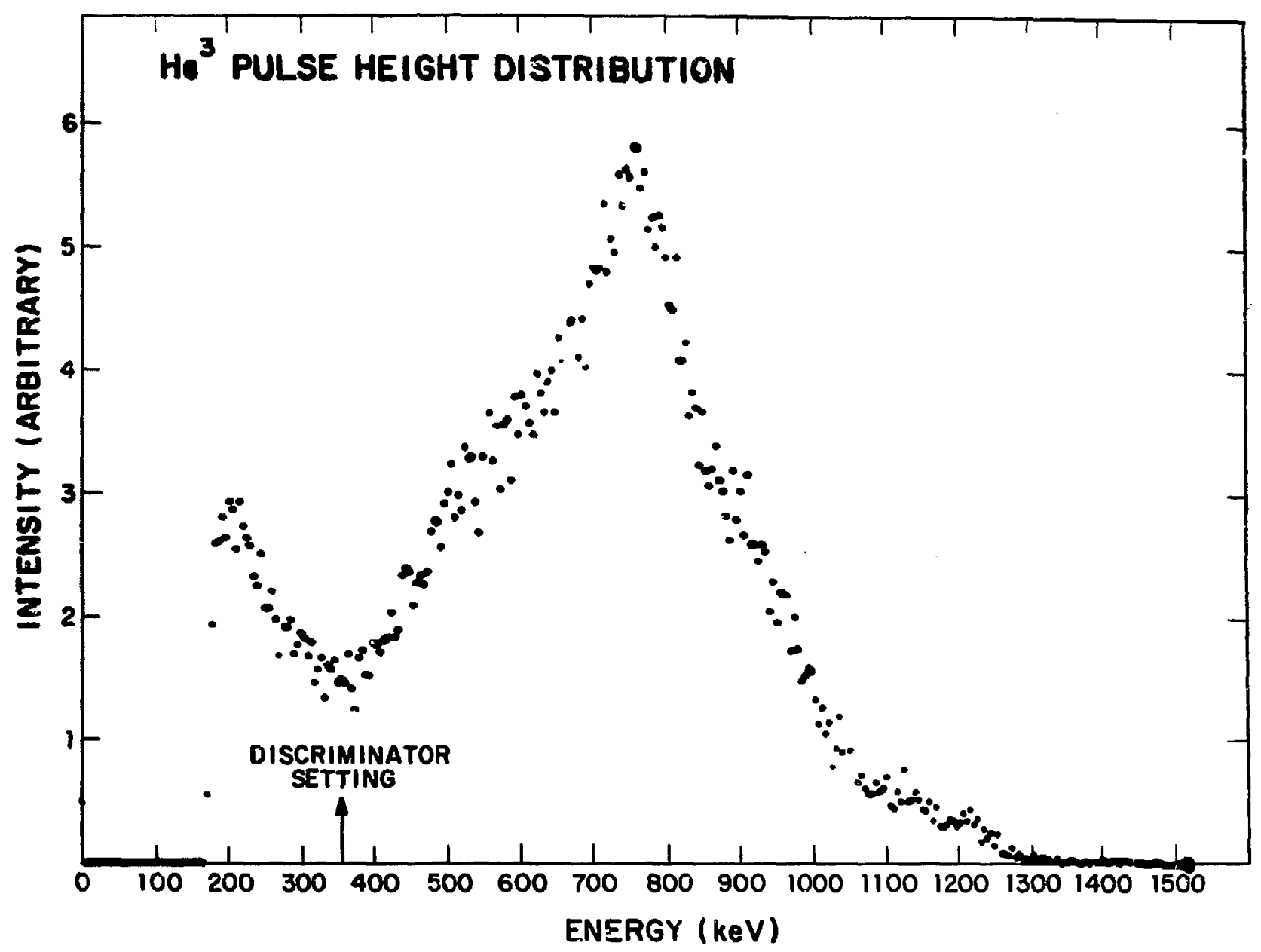

FIGURE 10 


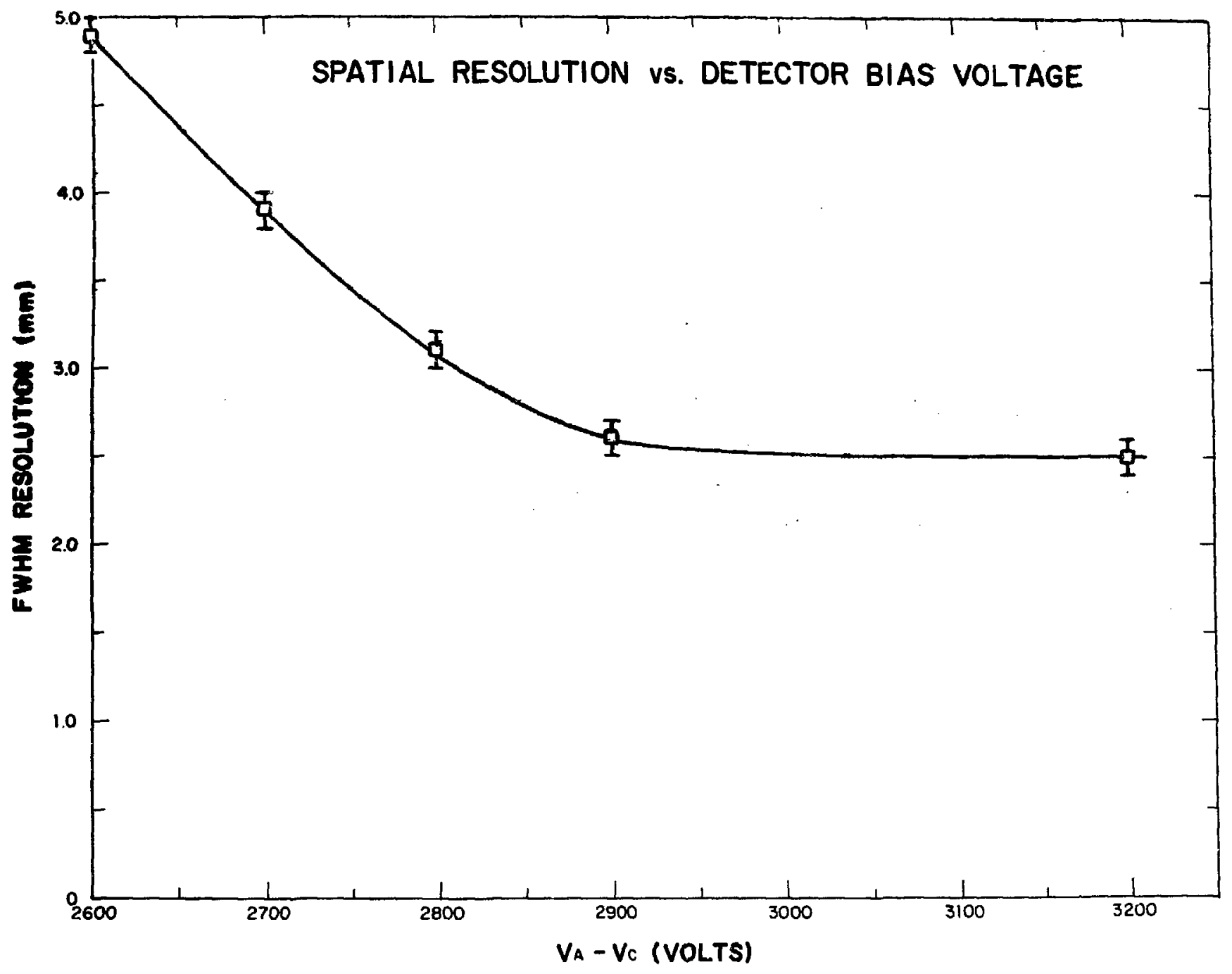

FIGURE 11 


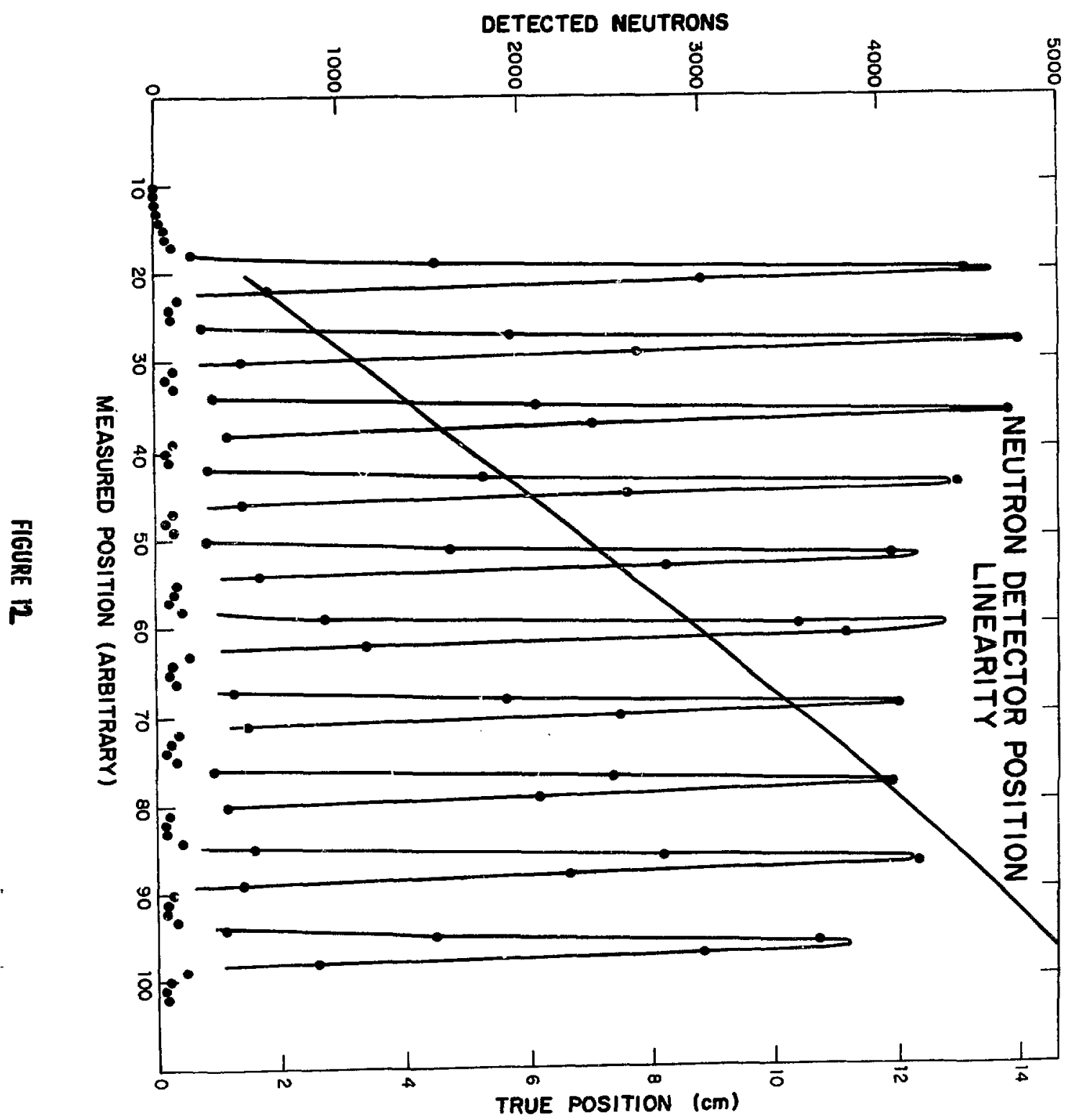




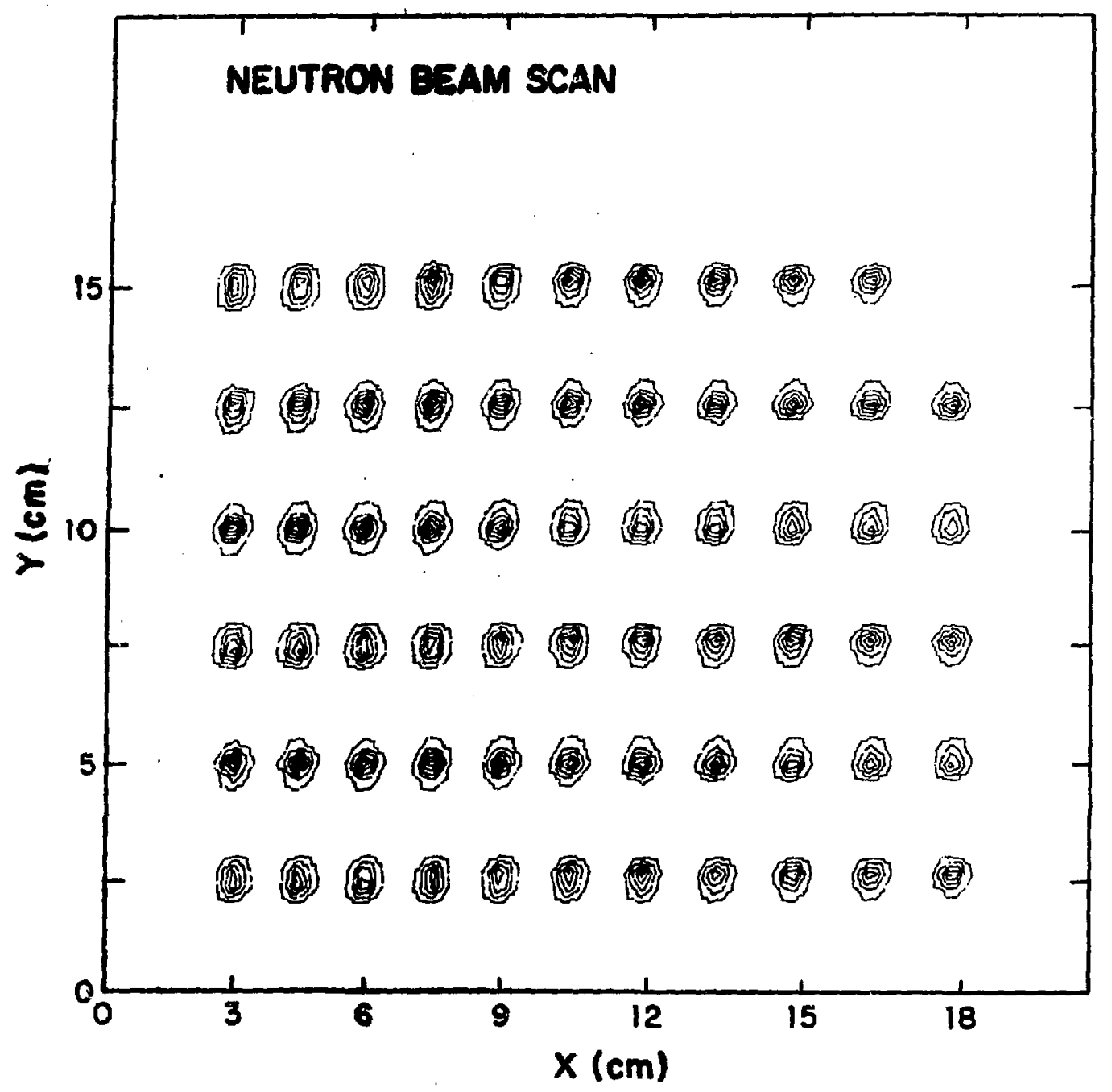

fretne is 


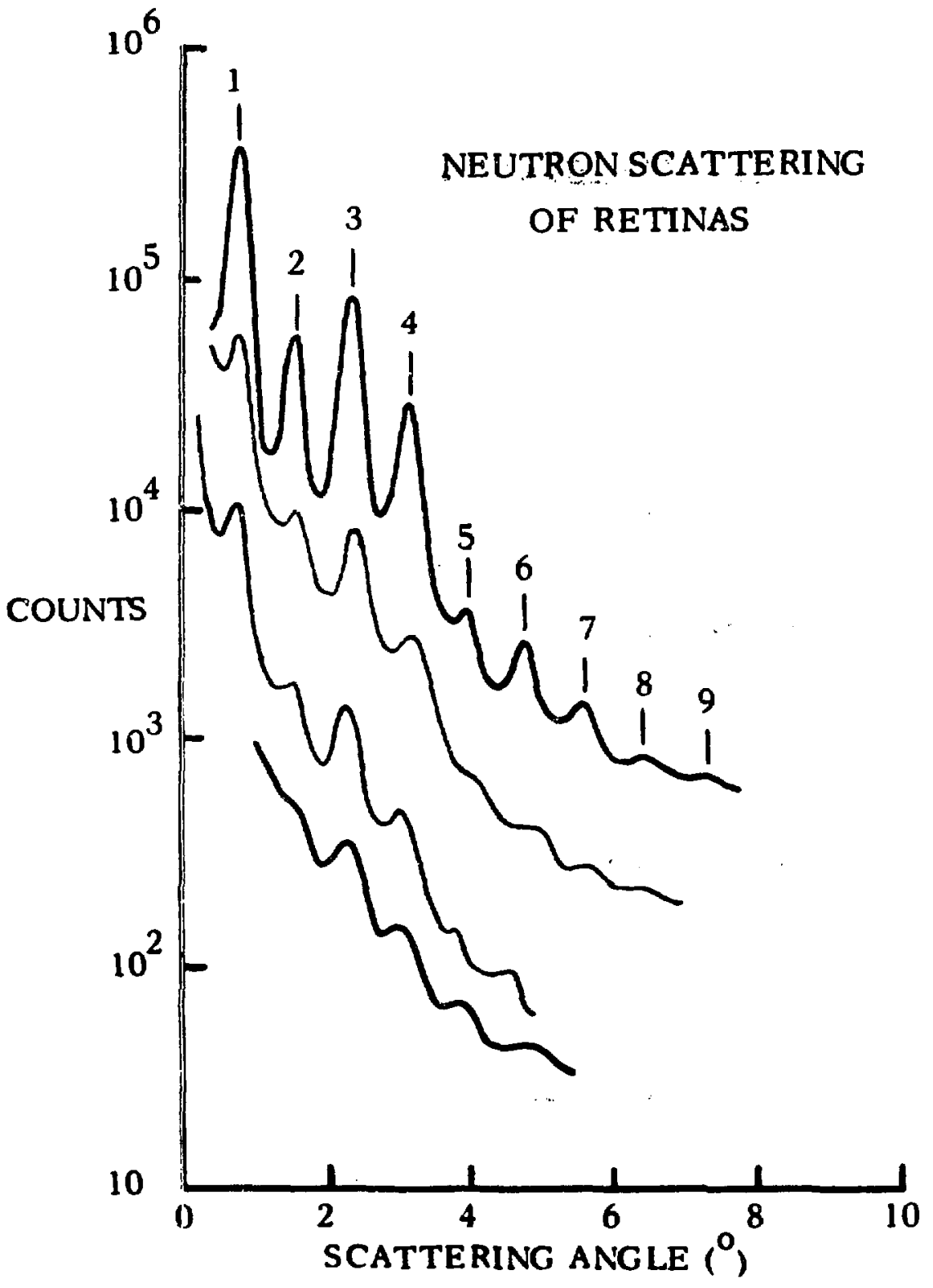

FIGURE 14 